\title{
A Novel Sensitivity Analysis Method in Structural Performance of Hydraulic Press
}

\author{
Peihao Zhu, Lianhong Zhang, Rui Zhou, Lihai Chen, \\ Bing Yu, and Qizhi Xie
}

School of Mechanical Engineering, Tianjin University, Tianjin 300072, China

Correspondence should be addressed to Peihao Zhu, zhupeihao_gp@163.com

Received 8 May 2012; Accepted 5 September 2012

Academic Editor: Alexei Mailybaev

Copyright (c) 2012 Peihao Zhu et al. This is an open access article distributed under the Creative Commons Attribution License, which permits unrestricted use, distribution, and reproduction in any medium, provided the original work is properly cited.

Sensitivity analysis plays a key role in structural optimization, but traditional methods of sensitivity analysis in strength and stiffness are time consuming and of high cost. In order to effectively carry out structural optimization of hydraulic press, this paper presents a novel sensitivity analysis method in structural performance of hydraulic press, which saves a great deal of time and design costs. The key dimension parameters of the optimization of design variables, which remarkably impact on the structural performance of hydraulic press, are efficiently selected. The impact order of various sensitivity parameters in strength and stiffness of machine tools is consistent with the sensitivity ranking of regression analysis. The research results provide the basis for the hydraulic machine design and references in research of machine tools and equipment.

\section{Introduction}

Sensitivity analysis (SA) is used to explain models structure and behaviour in response to inputs variation. SA is a method proposed on the basis of the initial design proposal from professional staff. It is a fundamental tool for supporting mathematical models development [1], because of its capability of explaining the variability in the outputs of the models themselves $[2,3]$, which achieve optimization of the system parameters. SA is traditionally used to identify the parameters with the highest impact on model outputs; it is also increasingly used to analyze model structure and behavior [4-6]. In this context, SA is recently recommended as a tool to be used iteratively during the process of model development [7], to assure coherence in mathematical formalizations, to avoid over parameterizations by driving simplification processes [1, 8], and to support the development of balanced models [9, 10]. Advanced SA techniques are also used in the framework of finite element modeling. Sensitivity analysis in the framework of finite element modeling has been put forward by [11, 12]; it has been 
developed in the solution of inverse problems in shape optimization in metal forming [13-15] or in material parameter identification [16-19]. In such inverse methods, the sensitivities with respect to the unknown material parameters or shape design variables have to be calculated by the direct differentiation method or the adjoint state method [20].

Hydraulic presses, both vertical and horizontal, are used in many industrial technologies. Vertical press applications include forging presses with flat dies, used for hot work to break down ingots and shape them into rolls, pressure vessels (mandrel forgings), forged bars, rods, plates, and so on. There are many structure parameters in hydraulic press. If all parameters are optimized for structural design variables of the complete machine, it leads the optimization model complex and enormous. Orthogonal design method [21, 22] is appropriate to sensitivity analysis of system parameters, which is adopted to analyze the structure parameters in hydraulic press. Since stiffness is proportional to the natural frequency in the same conditions, finite element analysis in structural performance of hydraulic press to strength and stiffness needed much computation time than the analysis of the modal analysis which extracts the natural frequency is more convenient and short time, which can achieve the same result in structural performance of hydraulic press. However, the traditional methods of the sensitivity analysis in strength and stiffness need a great amount of time and the fees. [23] made a research of the key parameters of hydraulic press with the welding composite frame. The key parameters of static and dynamic performance are obtained by using the quasi-static approach. [24] optimized the structural parameters of hydrocylinder by using improved genetic algorithm, which reduced the hydraulic cylinder weight.

In order to obtain high-sensitivity parameters, a novel sensitivity analysis method in structural performance of hydraulic press uses the modal analysis instead of strength and stiffness analysis for 100MN hydraulic press and optimizes the hydraulic machine by using parametric modeling. Figure 1 shows the research of the technology roadmap. The process can be described and achieved as follows.

Step 1. The python language is used in the key parts of $100 \mathrm{MN}$ hydraulic press.

Step 2. The orthogonal design is adopted to analyze the higher sensitivity influencing factors in strength and stiffness by extracting the natural frequencies. According to the table of orthogonal design, the modal analysis is conducted and the natural frequency is extracted.

Step 3. According to the results of the orthogonal design, the parameters of higher sensitivity are extracted by the regression analysis.

Step 4. According to the results of the regression analysis with the key parts of $100 \mathrm{MN}$ hydraulic press, this paper establishes the parameters model of $100 \mathrm{MN}$ hydraulic press.

Step 5. The whole structural FEA model based on the key dimension parameters and other parameters is constructed and analyzed in order to obtain the influence of the sensitivity parameters for strength and stiffness of the machine.

This paper is organized as follows: because the design of hydraulic presses is focused on the upper beam, lower beam, and column, Sections 1, 2, and 3 introduce our parameters model of the key parts with the python language in order to obtain key structural parameters. According to parameters of the key parts, Section 5 introduces our parameters model of $100 \mathrm{MN}$ hydraulic press, and the results and discussion are given in Section 4 . The whole 


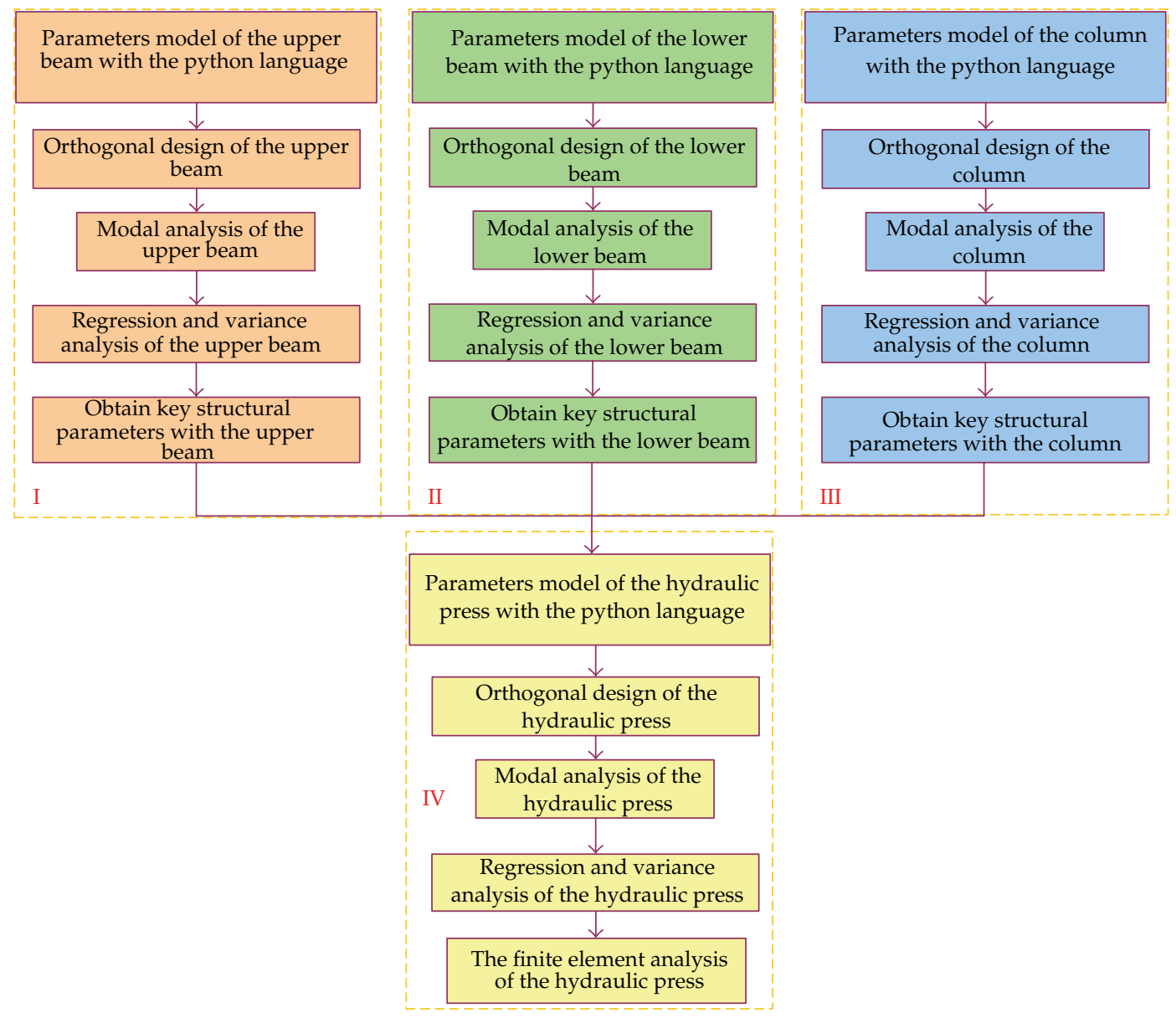

Figure 1: Research of the technology roadmap.

structural FEA model is established in order to obtain conclusion that the impact order of various sensitivity parameters to strength and stiffness of the machine is consistent with the sensitivity ranking of regression analysis; the higher sensitivity parameters of modal analysis have the greatest impact on strength and stiffness.

There is no need to directly conduct the strength and stiffness analysis of hydraulic press. The results of the whole structural FEA model showed that the impact order of various sensitivity parameters is consistent with the sensitivity ranking of regression analysis. These parameters of high sensitivity can be used as the focus of concern, such as the design variables of optimization. It is found that the higher sensitivity parameters can remarkably affect the structure performance of hydraulic press. The research results provide the basis for design of machine tool.

\section{Structure of 100MN Hydraulic Press}

Hydraulic press is the equipment of pressure working by hydraulic power, in which the pressure and speed can be regulated in a wide range. Hydraulic press plays an important role 


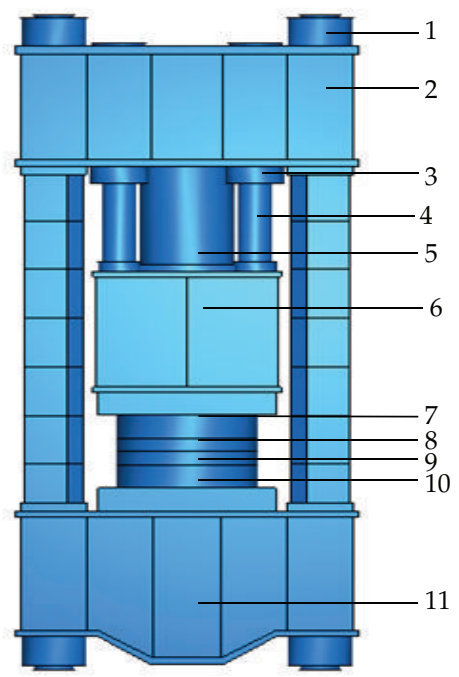

Figure 2: Structure of $100 \mathrm{MN}$ hydraulic press. 1: tie rod, 2: upper beam, 3: auxiliary of the cylinder, 4: auxiliary of the cylinder piston, 5: master cylinder piston, 6: ram, 7: upper plate, 8: upper die, 9: lower die, 10: lower plate, 11: lower beam.

in the departments of national economy. Now the product update cycle is getting shorter, so a higher request for hydraulic product design is put forward. Therefore, the design technology for hydraulic press is one of the important problems which puzzle the development of our country's hydraulic manufacture profession.

$100 \mathrm{MN}$ hydraulic press is one of the most common and most widely used structures, its structure is shown in Figure 2. The main structure of hydraulic press is made up of the work parts, including the cylinder and the moving crossbeam; the machine parts, including the upper beam, the lower beam, and the column; auxiliary parts, including a cylinder, moving workstation. The design of this machine is focused on the upper beam, lower beam, column, moving crossbeam, and master cylinder; if these components are satisfied with the design requirements and technical standards, the design of the whole machine is fulfilled. Therefore, the characteristics and data of each part in the machine must be analyzed and calculated.

\section{Structural Parameters Extraction of 100MN Precision Hydraulic Press}

\subsection{Extraction of Key Structural Parameters with the Upper Beam}

\subsubsection{Parameters Model of the Upper Beam with the Python Language}

Python [25] is a recent, general-purpose, high-level programming language. It is freely available and runs pretty much everywhere. Parametric modeling of the upper beam with python language is established in order to be submitted efficiently with a batch mode for the next modal analysis. Python language is a scripting language, which could obtain all the sizes of design part from the UG software, and all the geometric elements number of the part 


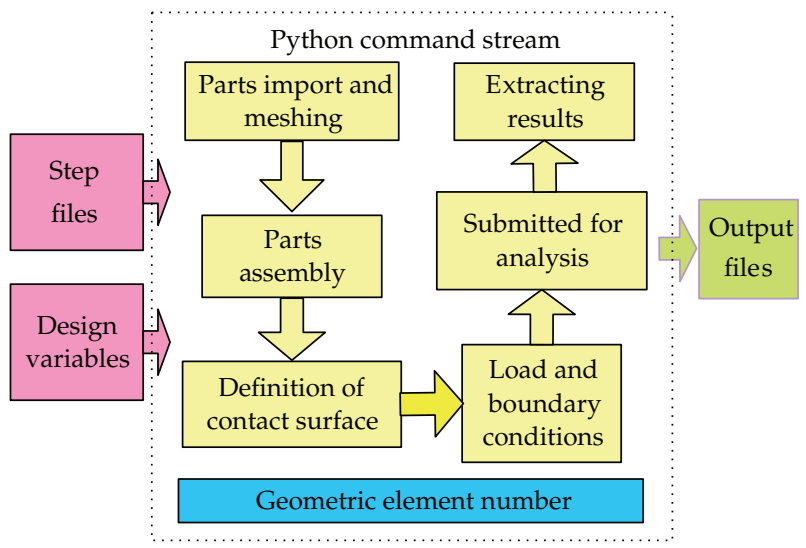

Figure 3: Flow chart of python command.

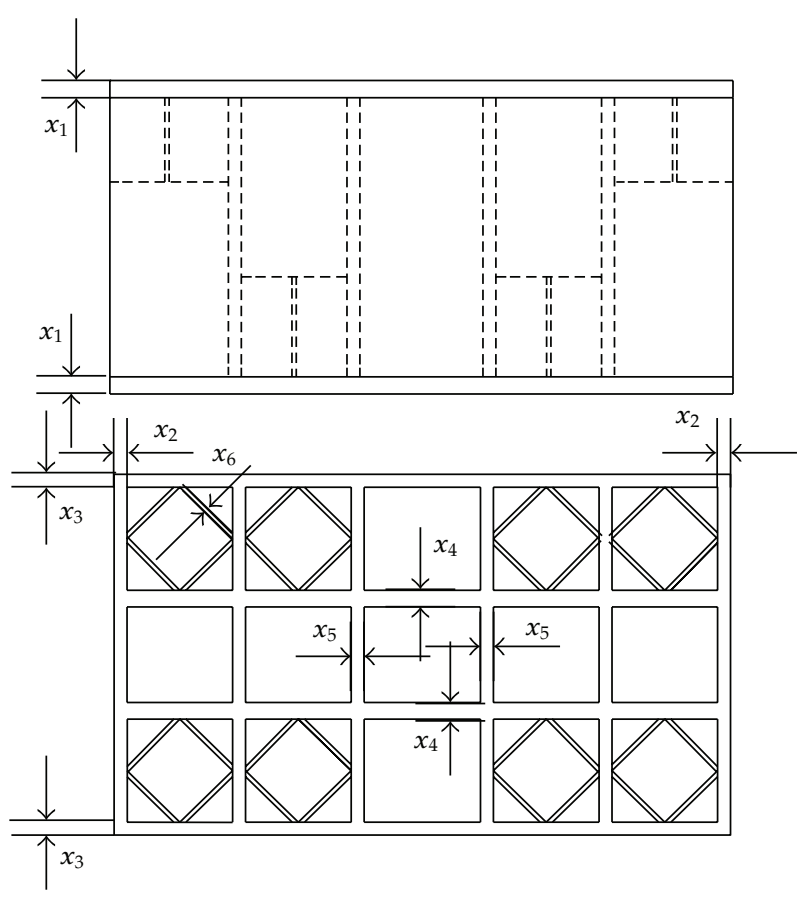

Figure 4: Parameters model of the upper beam.

could be obtained by querying functions. Therefore, the design variables and the file of step format are exported to command stream files before starting the command stream files of python. The procedure of python command stream is shown in Figure 3. Figure 4 shows the parameters model of the upper beam.

The above-mentioned process is encapsulated as a function in order to facilitate many times analysis and calculation. Its inputs contain geometry name of design variable, current size, the relevant files path, and output variable names and other information. The outputs are the results of the upper beam performance analysis. 


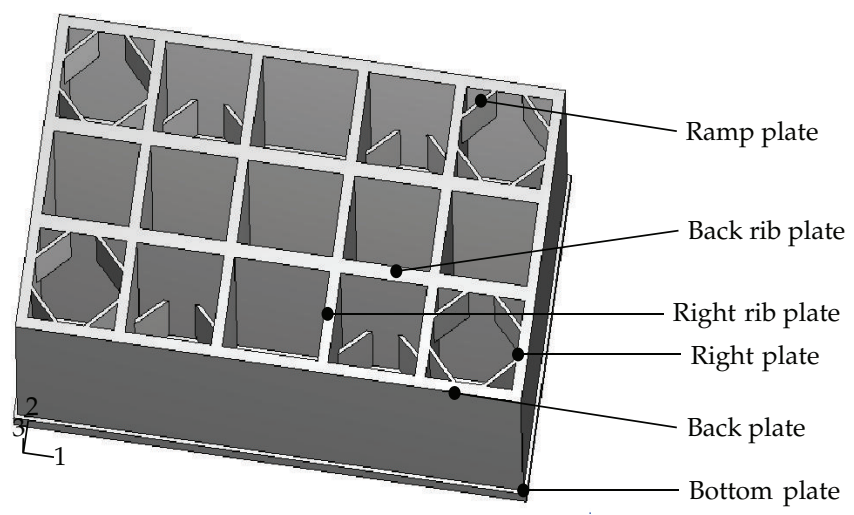

Figure 5: Structure of the upper beam.

The parameters model program of the upper beam is written as follow: $X_{1}=156$ \# the upper and lower plate thickness, $X_{2}=116$ \# the left and right plate thickness, $X_{3}=128$ \# the front and back plate thickness, $X_{4}=157$ \# the front and back rib plate thickness, $X_{5}=120$ \# the left and right rib plate thickness, $X_{6}=38$ \# the ramp plate thickness. Figure 5 illustrates the parameters model of the upper beam.

\subsubsection{Orthogonal Design of the Upper Beam}

Orthogonal design [26-28] is a valid method which makes use of orthogonal table $L_{n}\left(m^{k}\right)$ as a tool to arrange experiments and find out the optimal design with fewer experiments. In orthogonal table $L_{n}\left(m^{k}\right), n$ represents the number of rows, representing the number of experiments; $k$ represents the number of columns, namely, the number of factors; $m$ represents the number of factor levels.

There are six designable variables in the upper beam, every factor has five different levels, and there will be $5^{6}=15625$ total possible combinations of experiments. If we choose $L_{25}\left(5^{6}\right)$ orthogonal table, it only takes 25 combinations of experiments to obtain the desired results (Table 1 ).

The analysis of single part, such as the upper beam, lower beam, and column, are mainly discussed. Each factor of single part is determined by the initial design proposal from professional staff, because these parameters have important impact on structural performance of hydraulic press by the past practical experience. These parameters are representative. The thickness change of steel sheet in the actual production is easy to implement compare with the other factors such as length, width, and height of the whole part, which has influence on the inner structure parameters. The levels of each factor of single part are determined by steel plate thickness of the initial design, each parameter increments of the same mass increments and arithmetic sequence.

\subsubsection{Modal Analysis of the Upper Beam}

The modal analysis is the most basic and important part of analysis of dynamic character [29-31]. It is the modern method to study the dynamic character of structure. And it is 
Table 1: Orthogonal experimental table of six factors and five levels.

\begin{tabular}{|c|c|c|c|c|c|c|}
\hline \multicolumn{7}{|c|}{$L_{25}\left(5^{6}\right)$} \\
\hline Test no. & 1 & 2 & 3 & 4 & 5 & 6 \\
\hline 1 & 1 & 1 & 1 & 1 & 1 & 1 \\
\hline 2 & 1 & 2 & 2 & 2 & 2 & 2 \\
\hline 3 & 1 & 3 & 3 & 3 & 3 & 3 \\
\hline 4 & 1 & 4 & 4 & 4 & 4 & 4 \\
\hline 5 & 1 & 5 & 5 & 5 & 5 & 5 \\
\hline 6 & 2 & 1 & 2 & 3 & 4 & 5 \\
\hline 7 & 2 & 2 & 3 & 4 & 5 & 1 \\
\hline 8 & 2 & 3 & 4 & 5 & 1 & 2 \\
\hline 9 & 2 & 4 & 5 & 1 & 2 & 3 \\
\hline 10 & 2 & 5 & 1 & 2 & 3 & 4 \\
\hline 11 & 3 & 1 & 3 & 5 & 2 & 4 \\
\hline 12 & 3 & 2 & 4 & 1 & 3 & 5 \\
\hline 13 & 3 & 3 & 5 & 2 & 4 & 1 \\
\hline 14 & 3 & 4 & 1 & 3 & 5 & 2 \\
\hline 15 & 3 & 5 & 2 & 4 & 1 & 3 \\
\hline 16 & 4 & 1 & 4 & 2 & 5 & 3 \\
\hline 17 & 4 & 2 & 5 & 3 & 1 & 4 \\
\hline 18 & 4 & 3 & 1 & 4 & 2 & 5 \\
\hline 19 & 4 & 4 & 2 & 5 & 3 & 1 \\
\hline 20 & 4 & 5 & 3 & 1 & 4 & 2 \\
\hline 21 & 5 & 1 & 5 & 4 & 3 & 2 \\
\hline 22 & 5 & 2 & 1 & 5 & 4 & 3 \\
\hline 23 & 5 & 3 & 2 & 1 & 5 & 4 \\
\hline 24 & 5 & 4 & 3 & 2 & 1 & 5 \\
\hline 25 & 5 & 5 & 4 & 3 & 2 & 1 \\
\hline
\end{tabular}

the powerful tool to design and evaluate structure of product. The natural frequency and deformation amplitude of system could be acquired by modal analysis.

From the variation principle of elastic mechanics, the dynamic balance equation of the upper beam with multiple degree of freedom is as follows.

$$
[M]\{\ddot{u}\}+[C]\{\dot{u}\}+[K]\{u\}=\{P(t)\}+\{N\}+\{Q\},
$$

where $[M],[C]$, and $[K]$ are referred to, respectively, as the mass, damping, and stiffness matrices. The matrices are $n \times n$ square matrices, where $n$ is the number of degrees of freedom of the system. $\{P(t)\}$ is the external force function vector, $\{N\}$ is the nonlinear external force vector related with $\{\dot{u}\}$ and $\{u\},\{Q\}$ is the boundary constrain counterforce vector, $\{u\}$ is the shifting vector, $\{\dot{u}\}$ is the speed vector, and $\{\ddot{u}\}$ is the acceleration vector.

The natural frequency and vibration catalog represent the dynamic characters. The modal of the upper beam is analyzed. The natural frequency of the $i$ th modal is obtained. The first natural modal is shown in Figure 6 and Table 2. 
Table 2: The results of modal analysis and orthogonal experimental data with the upper beam.

\begin{tabular}{|c|c|c|c|c|c|c|c|}
\hline $\begin{array}{l}\text { Six factors } \\
\text { and five } \\
\text { levels }\end{array}$ & $\begin{array}{l}\quad X_{1} \\
\text { The upper } \\
\text { and lower } \\
\text { plate } \\
\text { thickness }\end{array}$ & $\begin{array}{l}\qquad X_{2} \\
\text { The left } \\
\text { and right } \\
\text { plate } \\
\text { thickness }\end{array}$ & $\begin{array}{l}\qquad X_{3} \\
\text { The front } \\
\text { and back } \\
\text { plate } \\
\text { thickness }\end{array}$ & $\begin{array}{l}X_{4} \\
\text { The front and } \\
\text { back rib plate } \\
\text { thickness }\end{array}$ & $\begin{array}{l}\qquad X_{5} \\
\text { The left and } \\
\text { right rib plate } \\
\text { thickness }\end{array}$ & $\begin{array}{l}\qquad X_{6} \\
\text { The ramp } \\
\text { plate } \\
\text { thickness }\end{array}$ & $\begin{array}{c}Y \\
\text { The } \\
\text { natural } \\
\text { frequency }\end{array}$ \\
\hline 1 & 156 & 116 & 128 & 157 & 120 & 38 & 164.10 \\
\hline 2 & 158 & 116 & 134 & 159 & 124 & 42 & 163.78 \\
\hline 3 & 160 & 116 & 132 & 151 & 122 & 36 & 164.63 \\
\hline 4 & 162 & 116 & 126 & 155 & 116 & 40 & 165.39 \\
\hline 5 & 164 & 116 & 130 & 153 & 118 & 44 & 165.26 \\
\hline 6 & 156 & 118 & 130 & 155 & 122 & 42 & 163.53 \\
\hline 7 & 158 & 118 & 128 & 153 & 116 & 36 & 164.55 \\
\hline 8 & 160 & 118 & 134 & 157 & 118 & 40 & 164.31 \\
\hline 9 & 162 & 118 & 132 & 159 & 120 & 44 & 164.53 \\
\hline 10 & 164 & 118 & 126 & 151 & 124 & 38 & 165.30 \\
\hline 11 & 156 & 120 & 126 & 159 & 118 & 36 & 164.01 \\
\hline 12 & 158 & 120 & 130 & 151 & 120 & 40 & 163.90 \\
\hline 13 & 160 & 120 & 128 & 155 & 124 & 44 & 164.03 \\
\hline 14 & 162 & 120 & 134 & 153 & 122 & 38 & 164.43 \\
\hline 15 & 164 & 120 & 132 & 157 & 116 & 42 & 164.96 \\
\hline 16 & 156 & 122 & 132 & 153 & 124 & 40 & 163.05 \\
\hline 17 & 158 & 122 & 126 & 157 & 122 & 44 & 163.66 \\
\hline 18 & 160 & 122 & 130 & 159 & 116 & 38 & 164.34 \\
\hline 19 & 162 & 122 & 128 & 151 & 118 & 42 & 164.54 \\
\hline 20 & 164 & 122 & 134 & 155 & 120 & 36 & 164.77 \\
\hline 21 & 156 & 124 & 134 & 151 & 116 & 44 & 162.88 \\
\hline 22 & 158 & 124 & 132 & 155 & 118 & 38 & 163.58 \\
\hline 23 & 160 & 124 & 126 & 153 & 120 & 42 & 164.01 \\
\hline 24 & 162 & 124 & 130 & 157 & 122 & 36 & 164.36 \\
\hline 25 & 164 & 124 & 128 & 159 & 124 & 40 & 164.56 \\
\hline
\end{tabular}

\subsubsection{Regression Analysis of the Upper Beam}

The regression analysis is a more commonly used quantitative analysis method [32, 33]. The so-called regression analysis is the quantity change relations between some random variables (dependent variables) and other or several variables (independent variable). The extracted relationship by the regression analysis usually is called the regression model.

After we use sample data (Table 2) to establish the regression equation, the general practical problems are not immediately used for the analysis. In practical problems, there are six factors (independent variable) that affect the dependent variable $y$; from all independent variables we hope to select the independent variables that have significant effect on $y$, to establish the regression equation. In the regression equation if we leave out the independent variables having significant effect on $y$, it will affect the fitting results.

Regression flow is shown in Figure 7. First of all, take coefficient of regression significance test on largest variable of partial correlation coefficient, which decide this variable 


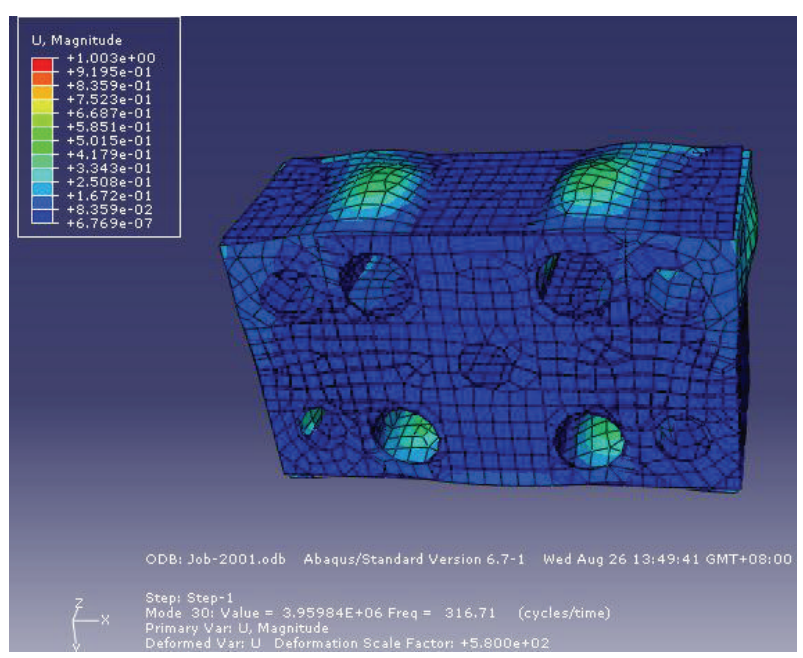

Figure 6: Results of modal analysis with the upper beam.

whether enter regression equation. Then calculate $F$-numbers of each variable in regression equation, biased $F$ test on the variable which biased $F$ value minimum, to decide whether this variable stays in regression equation or not. Repeat the calculating, until no variable is pulled into or rejected.

Let the dependent variable $y$ be an observable random variable, and independent variables $x_{1}, x_{2}, \ldots, x_{p}$ are generally variables. The general model of multivariate linear regression in sensitivity analysis of machining tool likes the following formula:

$$
y=\beta_{0}+\beta_{1} x_{1}+\beta_{2} x_{2}+\cdots+\beta_{p} x_{p}+\varepsilon, \quad \varepsilon \sim N\left(0, \sigma^{2}\right) .
$$

Sample data matrix is shown in

$$
\begin{gathered}
{\left[\begin{array}{c}
y_{1} \\
y_{2} \\
\vdots \\
y_{n}
\end{array}\right]=\left[\begin{array}{ccccc}
1 & x_{11} & x_{12} & \cdots & x_{1 p} \\
1 & x_{21} & x_{22} & \cdots & x_{2 p} \\
\vdots & \vdots & \vdots & \vdots & \vdots \\
1 & x_{n 1} & x_{n 2} & \cdots & x_{n p}
\end{array}\right]\left[\begin{array}{c}
\beta_{0} \\
\beta_{1} \\
\beta_{2} \\
\vdots \\
\beta_{p}
\end{array}\right],} \\
y_{n}=\beta_{0}+\beta_{1} x_{n 1}+\beta_{2} x_{n 2}+\cdots+\beta_{p} x_{n p}+\varepsilon_{n}, \\
y_{1}=\beta_{0}+\beta_{1} x_{11}+\beta_{2} x_{12}+\cdots+\beta_{p} x_{1 p}+\varepsilon_{1}, \\
y_{2}=\beta_{0}+\beta_{1} x_{21}+\beta_{2} x_{22}+\cdots+\beta_{p} x_{2 p}+\varepsilon_{2}, \\
\vdots \\
\vdots \\
y_{n}=\beta_{0}+\beta_{1} x_{n 1}+\beta_{2} x_{n 2}+\cdots+\beta_{p} x_{n p}+\varepsilon_{n},
\end{gathered}
$$




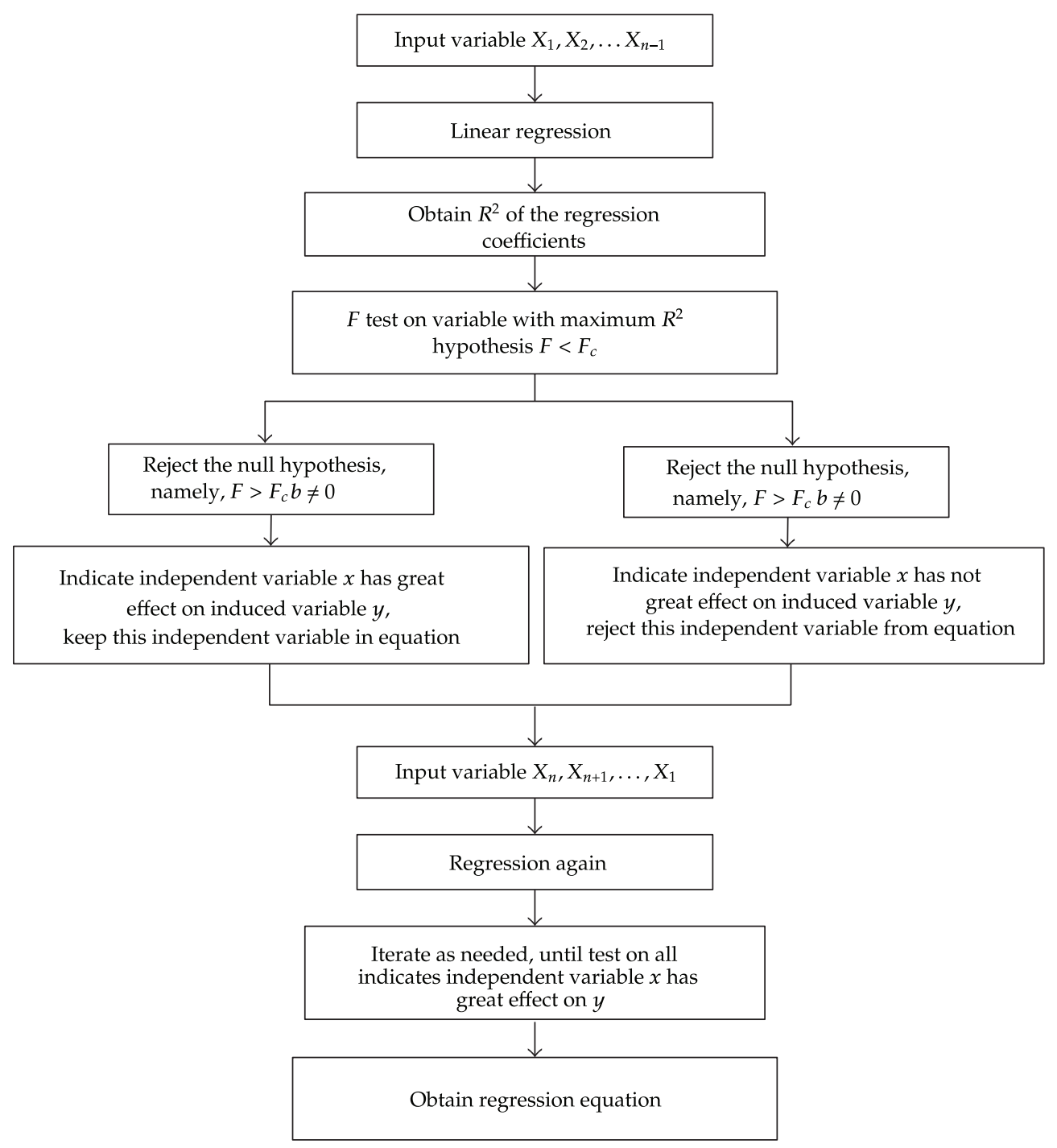

Figure 7: Procedure of regression equation.

where $y$ represents the natural frequency (expressed by demand generally), $\beta_{0}, \beta_{1}, \ldots \beta_{p}$ are unknown parameters, called regression coefficient; $x_{1}, x_{2}, \ldots x_{p}$ are the influence factors of natural frequency (explanatory variables); $\varepsilon$ denotes the random error, its mean is zero, and the variance is bigger than zero. That does not exist between the independent variable multicollinearity. In practice as long as the multicollinearity is weak, we can consider linear independence between the independent variables, and linear regression can be carried out.

The regression equation solves for the coefficients by minimizing the sum of the squares of the deviations of the data from the model (least-square fit). The least-square fit of the model as follow:

$$
Y=159.9456+0.1842 X_{1}+0.0940 X_{2}+0.0551 X_{3}+0.0011 X_{4}+0.0418 X_{5}+0.0468 X_{6}
$$


Table 3: Variance analysis table.

\begin{tabular}{lccccc}
\hline \multicolumn{2}{l}{ Source of variance Sum of squares } & Freedom of motion & Mean square & $F$ ratio & Significance \\
\hline Regression & $U$ & $m$ & $U / m$ & $F=\frac{U / m}{Q /(n-m-1)}$ \\
Residual error & $Q$ & $(n-m-1)$ & $Q /(n-m-1)$ & \\
Sum & $s_{y y}$ & $n-1$ & & \\
\hline
\end{tabular}

According to the regression equation to know, for upper beam of hydraulic press the biggest influence for the natural frequency is the upper and lower plate thickness, influences followed are the left and right plate thickness and little influences are the front and back rib plate thickness. It can be seen through the equation that values of $X_{1}$ and $X_{2}$ have greater impact on $Y$, which obtains the two higher sensitivity parameters of $X_{1}$ and $X_{2}$.

\subsubsection{Variance Analysis of the Upper Beam}

Analysis of variance (ANOVA) [34] is a statistical procedure for summarizing a classical linear model-a decomposition of sum of squares into a component for each source of variation in the model-along with an associated test (the $F$ test) of the hypothesis that any given source of variation in the model is zero. When applied to generalized linear models, multilevel models, and other extensions of classical regression, ANOVA can be extended in two different directions. First, the $F$ test can be used to compare models, to test the hypothesis that the simpler of the models is sufficient to explain the data. Second, the idea of variance decomposition can be interpreted as inference for the variances of batches of parameters (sources of variation) in multilevel regressions. Variance analysis table is shown in Table 3. The average value of the natural frequency is shown in

$$
\bar{y}=\frac{1}{n} \sum_{k=1}^{n} y_{k}
$$

Thus, the residual sum of squares and regression sum of squares are given by

$$
\begin{gathered}
U=\sum_{k=1}^{n}\left(\widehat{y}_{k}-\bar{y}\right)^{2}, \\
Q=\sum_{k=1}^{n}\left(y_{k}-\widehat{y}_{k}\right)^{2} .
\end{gathered}
$$

Total variation is the aggregate dispersion of the individual data values around the overall mean of all factor levels as shown in

$$
s_{y y}=U+Q=\sum_{k=1}^{n}\left(y_{k}-\bar{y}\right)^{2},
$$

where $y_{k}$ represents the natural frequency of upper beam, which could be acquired by modal analysis; $\bar{y}$ is the average value of the natural frequency $y_{k} ; \widehat{y}_{k}$ is regression value, which 
Table 4: Variance analysis of the upper beam.

\begin{tabular}{lccccc}
\hline Source of variance & Sum of squares & Freedom of motion & Mean square & $F$ ratio & Significance \\
\hline Regression & 704.4000 & 6 & 117.4000 & 738.3600 & $* *$ \\
Residual error & 2.8611 & 18 & 0.1590 & & \\
Sum & 707.2611 & 24 & & & \\
\hline
\end{tabular}

${ }^{*}$ The regression equation is remarkable.

could be acquired by regression equation; total variation can be split into two parts: $U$ and $Q$, and $U$ is regression sum of squares; $Q$ is residual sum of squares. Regression values mean the difference between the square and reflect the volatility caused by changes in the independent variable and its degree of freedom (since the number of variables); $s_{y y}=U+Q$, where $s_{y y}$ is total sum of squares (total variation).

The $F$ distribution is a right-skewed distribution used most commonly in Analysis of Variance (like ANOVA/MANOVA). The $F$ distribution is a ratio of two Chi-square distributions, and a specific $F$ distribution is denoted by the degrees of freedom for the numerator Chi-square and the degrees of freedom for the denominator Chi-square. When referencing the $F$ distribution, the numerator degrees of freedom are always given first, as switching the order of degrees of freedom changes the distribution (e.g., $F(10,12)$ does not equal $F(12,10)$ ). The $F$ distribution is an asymmetric distribution that has a minimum value of 0 , but no maximum value. The curve reaches a peak not far to the right of 0 and then gradually approaches the horizontal axis the larger the $F$ value is. The $F$ distribution approaches, but never quite touches, the horizontal axis. The formula of $F$ is obtained by

$$
F=\frac{U / m}{Q /(n-m-1)}
$$

where $m$ is the number of variables; $n$ is sum of all groups.

According to multiple linear regression equation, the table of variance analysis is obtained (Table 4 ). By the $F$ distribution table, the regression equation is remarkable (Table 4). The result of the test also proves that the equation of multiple linear regression is linear relation.

\subsection{Extraction of Key Structural Parameters with the Lower Beam}

\subsubsection{Parameters Model of the Lower Beam with the Python Language}

The parameters model program of the lower beam as follow: $X_{1}=116$ \# the lower plate thickness, $X_{2}=96$ \# the left and right plate thickness, $X_{3}=128$ \# the left and right rib plate thickness, $X_{4}=142$ \# the front and back rib plate thickness, $X_{5}=170$ \# the front and back plate thickness, $X_{6}=128$ \# the upper plate thickness. Figure 8 illustrates the parameters model of the lower beam.

\subsubsection{Orthogonal Design of the Lower Beam}

Orthogonal design is a statistical optimization method, which arranges multifactor test scheme based on one set of prepared standard table-orthogonal table. This paper uses 


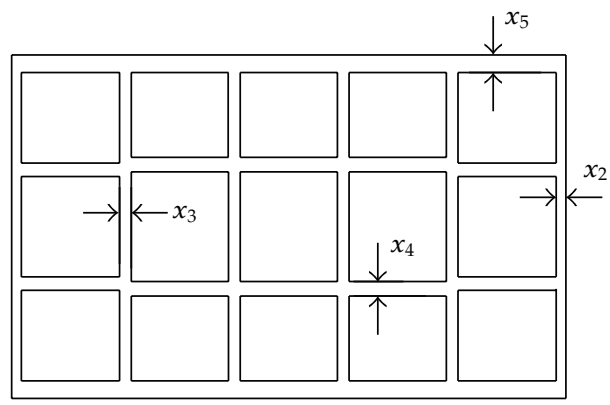

(a)

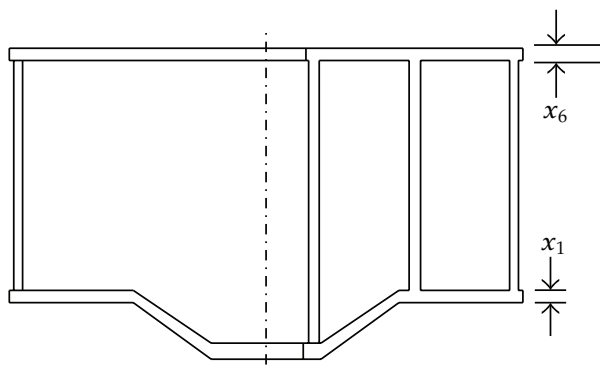

(b)

Figure 8: Parameters model of the lower beam.

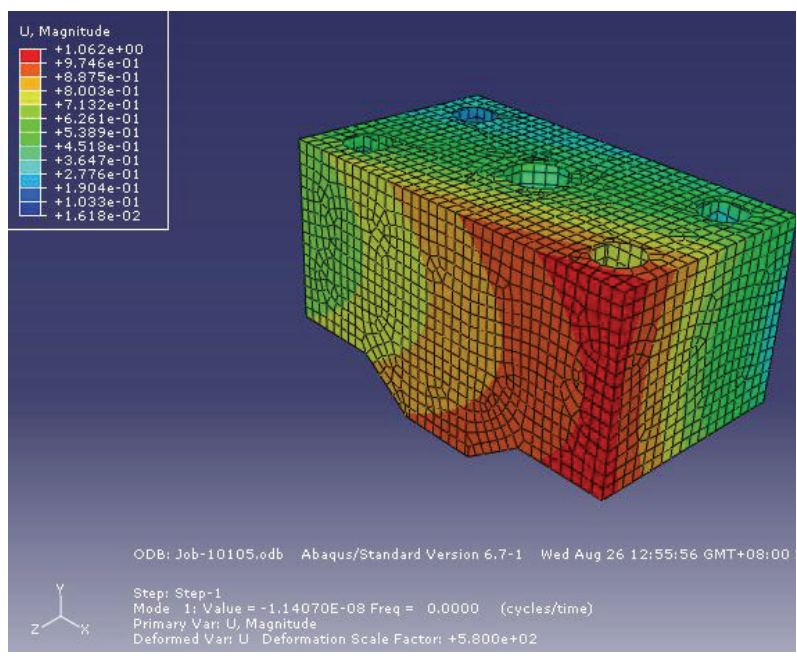

Figure 9: Results of modal analysis of the lower beam.

the orthogonal experimental design method to analyze hydraulic press of the lower beams. Figure 8 illustrates the parameters model of the lower beam. According to the influencing factors and designed level, design table is $L_{25}\left(5^{6}\right)$ and there are 25 kinds of calculating schemes. Statistics analysis is carried on calculating results and the significant degree of each factor is judged on the test index.

\subsubsection{Modal Analysis of the Lower Beam}

This paper uses the python language to establish the lower beam parameters model, which is analyzed by the modal method. According to orthogonal experimental table, it only requires 25 times of the modal analysis and each modal analysis of model parameter values is based on Table 5, and then submit the python command stream to the Abaqus, extract the first-order natural frequency, and use the batch mode to obtain the first-order natural frequency of 25 groups, and the results can be seen in Figure 9 and Table 5 . 
Table 5: Data results of Modal analysis of the lower beam.

\begin{tabular}{|c|c|c|c|c|c|c|c|}
\hline $\begin{array}{l}\text { Six factors } \\
\text { and five } \\
\text { levels }\end{array}$ & $\begin{array}{c}\quad X_{1} \\
\text { The lower } \\
\text { plate } \\
\text { thickness }\end{array}$ & $\begin{array}{c}\quad X_{2} \\
\text { The left and } \\
\text { right plate } \\
\text { thickness }\end{array}$ & $\begin{array}{c}X_{3} \\
\text { The left and } \\
\text { right rib plate } \\
\text { thickness }\end{array}$ & $\begin{array}{c}\quad X_{4} \\
\text { The front and } \\
\text { back rib plate } \\
\text { thickness }\end{array}$ & $\begin{array}{c}\quad X_{5} \\
\text { The front and } \\
\text { back plate } \\
\text { thickness }\end{array}$ & $\begin{array}{c}X_{6} \\
\text { The upper } \\
\text { plate } \\
\text { thickness }\end{array}$ & $\begin{array}{c}\text { Y } \\
\text { Natural } \\
\text { frequency }\end{array}$ \\
\hline 1 & 116 & 96 & 128 & 142 & 170 & 128 & 175.88 \\
\hline 2 & 118 & 96 & 134 & 144 & 174 & 132 & 176.27 \\
\hline 3 & 120 & 96 & 132 & 136 & 172 & 126 & 176.48 \\
\hline 4 & 122 & 96 & 126 & 140 & 166 & 130 & 177.33 \\
\hline 5 & 124 & 96 & 130 & 138 & 168 & 134 & 178.44 \\
\hline 6 & 116 & 98 & 130 & 140 & 172 & 132 & 176.11 \\
\hline 7 & 118 & 98 & 128 & 138 & 166 & 126 & 175.85 \\
\hline 8 & 120 & 98 & 134 & 142 & 168 & 130 & 176.98 \\
\hline 9 & 122 & 98 & 132 & 144 & 170 & 134 & 177.72 \\
\hline 10 & 124 & 98 & 126 & 136 & 174 & 128 & 176.98 \\
\hline 11 & 116 & 100 & 126 & 144 & 168 & 126 & 174.89 \\
\hline 12 & 118 & 100 & 130 & 136 & 170 & 130 & 176.15 \\
\hline 13 & 120 & 100 & 128 & 140 & 174 & 134 & 176.81 \\
\hline 14 & 122 & 100 & 134 & 138 & 172 & 128 & 176.73 \\
\hline 15 & 124 & 100 & 132 & 142 & 166 & 134 & 177.90 \\
\hline 16 & 116 & 102 & 132 & 138 & 174 & 130 & 175.41 \\
\hline 17 & 118 & 102 & 126 & 142 & 172 & 134 & 176.04 \\
\hline 18 & 120 & 102 & 130 & 144 & 166 & 128 & 175.89 \\
\hline 19 & 122 & 102 & 128 & 136 & 168 & 132 & 176.82 \\
\hline 20 & 124 & 102 & 134 & 140 & 170 & 126 & 176.51 \\
\hline 21 & 116 & 104 & 134 & 136 & 166 & 134 & 175.99 \\
\hline 22 & 118 & 104 & 132 & 140 & 168 & 128 & 175.33 \\
\hline 23 & 120 & 104 & 126 & 138 & 170 & 132 & 175.96 \\
\hline 24 & 122 & 104 & 130 & 142 & 172 & 126 & 175.57 \\
\hline 25 & 124 & 104 & 128 & 144 & 174 & 130 & 176.32 \\
\hline
\end{tabular}

\subsubsection{Regression Analysis of the Lower Beam}

The so-called regression analysis is based on a large number of observation data, function expression of regression relationship between the independent variable, and the dependent variable called the regression equation is established by using of mathematical statistics methods. This paper achieves the linear regression analysis.

The analysis results of multiple linear regression are shown as follows:

$$
Y=155.1471+0.1981 X_{1}+0.1343 X_{2}+0.0337 X_{3}+0.0287 X_{4}+0.0414 X_{5}+0.1353 X_{6}
$$

According to the regression equation to know, for the lower beam of hydraulic press the biggest influence for the natural frequency is the lower plate thickness, influences followed are the upper plate thickness, and little influences are the front and back rib plate thickness. 
Table 6: Regression equation of variance analysis of the lower beam.

\begin{tabular}{lccccc}
\hline Source of variance & Sum of squares & Freedom of motion & Mean square & F ratio & Significance \\
\hline Regression & 150.5780 & 6 & 25.1000 & 145.7610 & ${ }^{* *}$ \\
Residual error & 3.0990 & 18 & 0.1722 & & \\
Sum & 153.6770 & 24 & & & \\
\hline
\end{tabular}

${ }^{*}$ The regression equation is remarkable.

It can be seen through the equation that values of $X_{1}$ and $X_{6}$ have greater impact on $Y$ (natural frequency), then obtain the highest sensitivity of the two parameters: the lower plate thickness $\left(X_{1}\right)$, the upper plate thickness $\left(X_{6}\right)$.

According to multiple linear regression equation, the table of variance analysis (Table 6) can be obtained.

By the $F$ distribution table, when there is remarkable degree of $\alpha=0.01, F 0.01(6,18)=$ 4.01. Because of $F=145.761 \gg 4.01$, that is, the $F \gg F 0.01$, so the regression equation is very remarkable (Table 6). The results of the test prove that multiple linear regression equation is linear relation, and the regression equation is very remarkable.

From the formula (3.9), we come to the conclusion that sort effects of the design parameters on the lower beam to the natural frequency: $X_{1}, X_{6}, X_{2}, X_{5}, X_{3}, X_{4}$, that is to say, $X_{1}$ and $X_{6}$ are the upper beam sensitive parameters.

\subsection{Extraction of Key Structural Parameters with the Column}

\subsubsection{Parameters Model of the Column with the Python Language}

The parameters model program of the column as follow: from part import *from material import *from section import *from assembly import *from step import *from interaction import *from load import *from mesh import * from job import * from sketch import * from visualization import *from connector Behavior import*. $X_{1}=116$ \# The top to the first rib plates, $X_{2}=96$ \# The first to the second rib plates, $X_{3}=128$ \# The remaining distance between rib plates, $X_{4}=142$ \# The roof column width, $X_{5}=170$ \# The column plates thickness, $X_{6}=128$ \# The rib plates thickness. Figure 10 illustrates the parameters model of the column.

\subsubsection{Orthogonal Design of the Column}

This paper uses the orthogonal experimental design method to analyze six parameters of the columns (Figure 10) and arranges five levels for each parameter as a factor. According to the six factors and five levels of orthogonal design table, obtain six factors and five levels of orthogonal experimental data of the column. Six factors contain the top to the first rib plates $\left(X_{1}\right)$, the first to the second rib plates $\left(X_{2}\right)$, the remaining distance between rib plates $\left(X_{3}\right)$, the roof column width $\left(X_{4}\right)$, the column plates thickness $\left(X_{5}\right)$, and the rib plates thickness $\left(X_{6}\right)$.

\subsubsection{Modal Analysis of the Column}

This paper uses python language to establish the model of the column, which is analyzed by the modal method. According to orthogonal experimental table, it only requires 25 times of 


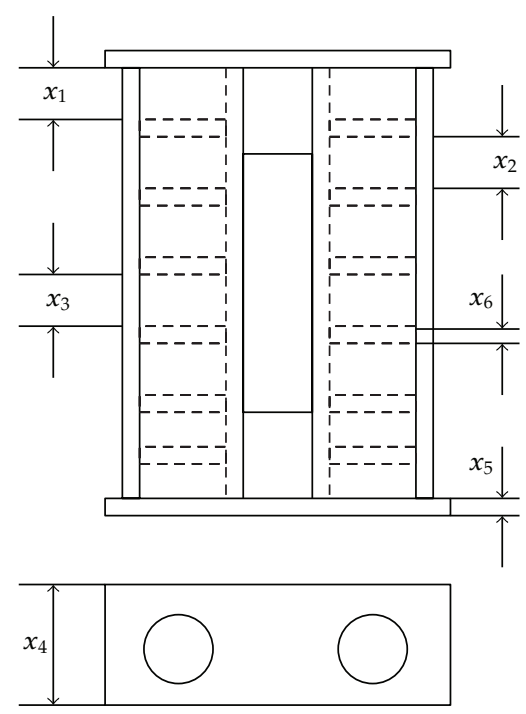

Figure 10: Parameters model of the column.

the modal analysis and each modal analysis of model parameter values is based on Table 7, and then submit the python command stream to the Abaqus, extract the first-order natural frequency, and use the batch mode to quickly extract the first-order natural frequency of 25, and the results are shown in (Figure 10 and Table 6).

The essence of modal analysis is to solve the matrix eigenvalues, according to the table of orthogonal design, which only needs the modal analysis of 25, times, and each model parameter is based on Table 1 . The python command stream is submitted to the Abaqus, which extracts the first order natural frequency (Table 7 and Figure 11). The first order natural frequency of 25 groups is quickly extracted by using the batch mode, and the results of batch mode can be seen in Table 7 .

\subsubsection{Regression Analysis of the Lower Beam}

Regression analysis is a parametric method that requires a specification of the analytical expression of the functional form that links the inputs and outputs. The equation of multiple linear regression with the lower beam is shown as follows:

$$
Y=18.4176+0.0003 X_{1}+0.0007 X_{2}+0.0006 X_{3}+0.0002 X_{4}+0.004 X_{5}+X_{6}
$$

According to the regression equation to know, for the column the biggest influence for the natural frequency is the rib plates thickness, influences followed are the column plates thickness, and little influences are the roof column width.

By the $F$ distribution table, when there is remarkable degree of $\alpha=0.01, F 0.01(6,18)=$ 4.01. Because of $F=169.1700 \gg 4.01$, that is, the $F \gg F 0.01$, so the regression equation is very remarkable (Table 8 ). The test proves that multiple linear regression equation is linear relation. 
Table 7: Modal analysis results of the column.

\begin{tabular}{|c|c|c|c|c|c|c|c|}
\hline $\begin{array}{l}\text { Six factors } \\
\text { and five } \\
\text { levels }\end{array}$ & $\begin{array}{l}X_{1} \\
\text { The top to } \\
\text { the first } \\
\text { rib plates }\end{array}$ & $\begin{array}{c}\quad X_{2} \\
\text { The first to } \\
\text { the second } \\
\text { rib plates }\end{array}$ & $\begin{array}{c}X_{3} \\
\text { The remaining } \\
\text { distance between } \\
\text { rib plates }\end{array}$ & $\begin{array}{l}X_{4} \\
\text { The roof } \\
\text { column } \\
\text { width }\end{array}$ & $\begin{array}{c}X_{5} \\
\text { The column } \\
\text { plates } \\
\text { thickness } \\
\end{array}$ & $\begin{array}{c}X_{6} \\
\text { The rib } \\
\text { plates } \\
\text { thickness }\end{array}$ & $\begin{array}{c}\Upsilon \\
\text { Natural } \\
\text { frequency }\end{array}$ \\
\hline 1 & 800 & 800 & 925 & 1050 & 135 & 45 & 17.953 \\
\hline 2 & 900 & 800 & 1150 & 1100 & 150 & 55 & 18.016 \\
\hline 3 & 1000 & 800 & 1075 & 900 & 143 & 40 & 18.063 \\
\hline 4 & 1100 & 800 & 850 & 1000 & 120 & 50 & 17.906 \\
\hline 5 & 1200 & 800 & 1000 & 950 & 127 & 60 & 17.859 \\
\hline 6 & 800 & 900 & 1000 & 1000 & 143 & 55 & 17.965 \\
\hline 7 & 900 & 900 & 925 & 950 & 120 & 40 & 17.903 \\
\hline 8 & 1000 & 900 & 1150 & 1050 & 127 & 50 & 17.960 \\
\hline 9 & 1100 & 900 & 1075 & 1100 & 135 & 60 & 17.921 \\
\hline 10 & 1200 & 900 & 850 & 900 & 150 & 45 & 18.072 \\
\hline 11 & 800 & 1000 & 850 & 1100 & 127 & 40 & 17.773 \\
\hline 12 & 900 & 1000 & 1000 & 900 & 135 & 50 & 17.779 \\
\hline 13 & 1000 & 1000 & 925 & 1000 & 150 & 60 & 17.842 \\
\hline 14 & 1100 & 1000 & 1150 & 950 & 143 & 45 & 17.859 \\
\hline 15 & 1200 & 1000 & 1075 & 1050 & 120 & 55 & 17.799 \\
\hline 16 & 800 & 1100 & 1075 & 950 & 150 & 50 & 17.768 \\
\hline 17 & 900 & 1100 & 850 & 1050 & 143 & 60 & 17.778 \\
\hline 18 & 1000 & 1100 & 1000 & 1100 & 120 & 45 & 17.772 \\
\hline 19 & 1100 & 1100 & 925 & 900 & 127 & 55 & 17.785 \\
\hline 20 & 1200 & 1100 & 1150 & 1000 & 135 & 40 & 16.739 \\
\hline 21 & 800 & 1200 & 1150 & 900 & 120 & 60 & 17.656 \\
\hline 22 & 900 & 1200 & 1075 & 1000 & 127 & 45 & 17.833 \\
\hline 23 & 1000 & 1200 & 850 & 950 & 135 & 55 & 17.766 \\
\hline 24 & 1100 & 1200 & 1000 & 1050 & 143 & 40 & 17.941 \\
\hline 25 & 1200 & 1200 & 925 & 1100 & 150 & 50 & 17.937 \\
\hline
\end{tabular}

Table 8: Variance analysis of the column.

\begin{tabular}{lccccc}
\hline Source of variance & Sum of squares & Freedom of motion & Mean square & $F$ ratio & Significance \\
\hline Regression & 55.5200 & 6 & 9.250 & 169.1700 & $* *$ \\
Residual error & 0.9842 & 18 & 0.0547 & & \\
Sum & 56.5042 & 24 & & & \\
\hline
\end{tabular}

${ }^{*}$ The regression equation is remarkable.

According to multiple linear regression equation in a similar way, the results of variance analysis are shown in Table 8.

From the formula, we can come to the conclusion that sort effects of the design parameters on the lower beam to the natural frequency: $X_{6}, X_{5}, X_{2}, X_{3}, X_{1}, X_{4}$, that is to say, $X_{6}$ and $X_{5}$ are the column sensitive parameters. 


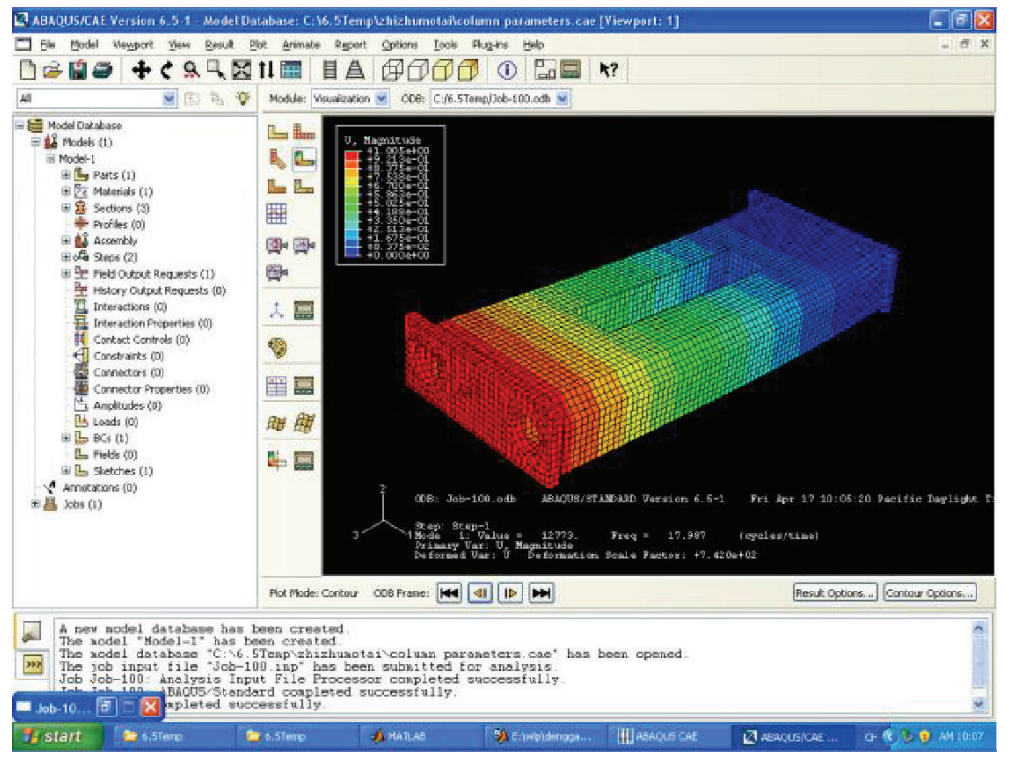

Figure 11: Results of modal analysis of the column.

\section{The Finite Element Analysis of Hydraulic Press}

The natural frequency, also known as the fundamental frequency, refers to the number of times a given event will happen in a second. According to fundamentals of vibration analysis, the stiffness of machine tools is proportional to the natural frequency in the same conditions. Enhancing the natural frequency improves the dynamic performance of machine tools to satisfy the performance requirement of high stiffness and light mass of the $100 \mathrm{MN}$ hydraulic press. So the natural frequency can be used to evaluate the performances of strength and stiffness in a sense. Enhancing the natural frequency, reducing the mass, and improving the stiffness are very important to improve the machine performance.

According to the novel method of sensitivity analysis in structural performance of hydraulic press, the key dimension parameters are efficiently obtained: the column of $X_{5}$ (the column plates thickness), $X_{6}$ (the rib plates thickness), the lower beam of $X_{1}$ (the lower plate thickness), $X_{6}$ (the upper plate thickness), the upper beam of $X_{1}$ (the upper and lower plate thickness), and $X_{4}$ (the front and back rib plate thickness). The 100MN hydraulic press of the whole structural model based on the key dimension parameters and other parameters is analyzed in order to verify the influence of the sensitivity parameters on strength and stiffness of the machine and identify the impact order of various sensitivity parameters to strength and stiffness of the machine which is consistent with the sensitivity ranking of regression analysis. The whole structural FEA model based on key dimension parameters and other dimension parameters is determined by modal analysis, regression analysis, and random selection.

The results are shown in Figure 12. The higher sensitivity parameters of modal analysis compared with other parameters have greater impact on strength and stiffness. The results of the whole structural FEA model have showed that the impact order of various sensitivity parameters to strength and stiffness of the machine has been consistent with the sensitivity ranking of regression analysis. 


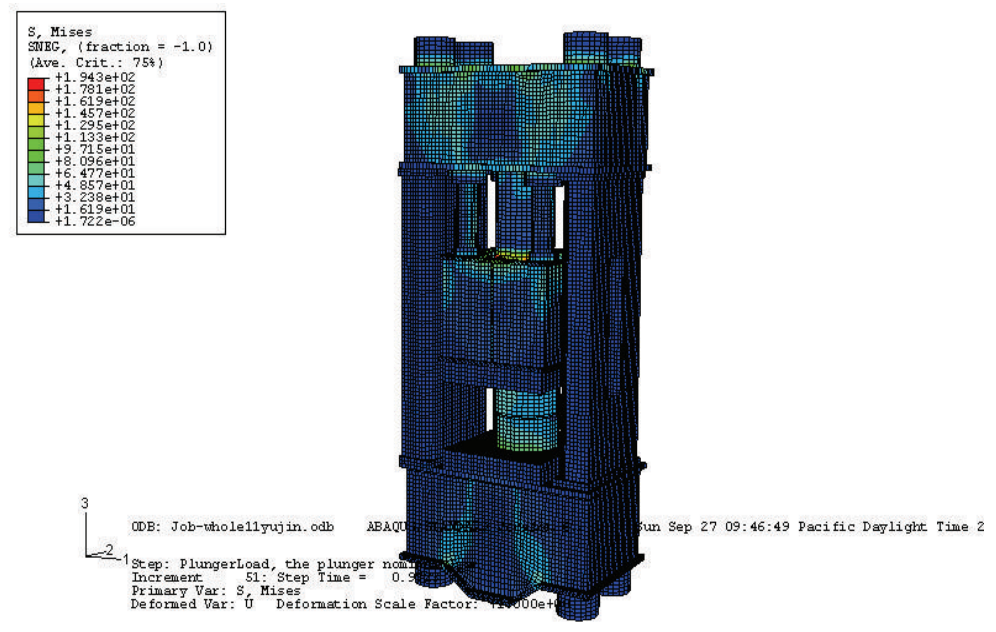

Figure 12: Stress analysis of hydraulic press.

\section{Conclusion}

This paper has conducted the study on the higher sensitivity parameters of hydraulic press with a novel sensitivity analysis method in structural performance. The results have shown that (1) the higher sensitivity parameters had the greatest impact on strength and stiffness and increasing the higher sensitivity parameters remarkably has enhanced the strength and stiffness of machine tools (2). The results of the whole structural FEA model have showed that the impact order of various sensitivity parameters has been consistent with the sensitivity ranking of regression analysis. These parameters of high sensitivity have been used as the focus of concern, such as the design variables of optimization. It has been found that the higher sensitivity parameters remarkably affected the structure performance of hydraulic press (3). The finite element analysis in structural performance of hydraulic press to strength and stiffness has needed much computation time than the modal analysis, and the modal analysis which has extracted the natural frequency has been more convenient and of short time in structural performance of hydraulic press, which has achieved the same result in structural performance of hydraulic press (4). There has been no need to conduct directly the strength and stiffness analysis in structural performance of hydraulic press by novel sensitivity analysis method. The research results have provided the basis for the forging machine design, and the methods can also provide reference to machine tools and equipment research.

\section{Acknowledgments}

The authors are grateful to the financial support of the National Natural Science Foundation of China under Grant no. 50805101. The paper is also supported by major projects for science and technology development for advanced CNC machines (2009ZX04004-031-04).

\section{References}

[1] S. Tarantola and A. Saltelli, "SAMO 2001: methodological advances and innovative applications of sensitivity analysis," Reliability Engineering and System Safety, vol. 79, no. 2, pp. 121-122, 2001. 
[2] F. Campolongo, J. Cariboni, and A. Saltelli, "An effective screening design for sensitivity analysis of large models," Environmental Modelling and Software, vol. 22, no. 10, pp. 1509-1518, 2007.

[3] J. Cariboni, D. Gatelli, R. Liska, and A. Saltelli, "The role of sensitivity analysis in ecological modelling," Ecological Modelling, vol. 203, no. 1-2, pp. 167-182, 2007.

[4] R. Confalonieri, G. Bellocchi, S. Bregaglio, M. Donatelli, and M. Acutis, "Comparison of sensitivity analysis techniques: a case study with the rice model WARM," Ecological Modelling, vol. 221, no. 16, pp. 1897-1906, 2010.

[5] R. Confalonieri, G. Bellocchi, S. Tarantola, M. Acutis, M. Donatelli, and G. Genovese, "Sensitivity analysis of the rice model WARM in Europe: exploring the effects of different locations, climates and methods of analysis on model sensitivity to crop parameters," Environmental Modelling and Software, vol. 25, no. 4, pp. 479-488, 2010.

[6] R. Confalonieri, S. Bregaglio, and M. Acutis, "A proposal of an indicator for quantifying model robustness based on the relationship between variability of errors and of explored conditions," Ecological Modelling, vol. 221, no. 6, pp. 960-964, 2010.

[7] A. J. Jakeman, R. A. Letcher, and J. P. Norton, "Ten iterative steps in development and evaluation of environmental models," Environmental Modelling and Software, vol. 21, no. 5, pp. 602-614, 2006.

[8] M. Ratto, S. Tarantola, and A. Saltelli, "Sensitivity analysis in model calibration: GSA-GLUE approach," Computer Physics Communications, vol. 136, no. 3, pp. 212-224, 2001.

[9] R. Confalonieri, "Monte Carlo based sensitivity analysis of two crop simulators and considerations on model balance," European Journal of Agronomy, vol. 33, no. 2, pp. 89-93, 2010.

[10] A. J. Jakeman, R. A. Letcher, and J. P. Norton, "Ten iterative steps in development and evaluation of environmental models," Environmental Modelling and Software, vol. 21, no. 5, pp. 602-614, 2006.

[11] J. J. Tsay and J. S. Arora, "Nonlinear structural design sensitivity analysis for path dependent problems. I. General theory," Computer Methods in Applied Mechanics and Engineering, vol. 81, no. 2, pp. 183-208, 1990.

[12] J. J. Tsay, J. E. B. Cardoso, and J. S. Arora, “Nonlinear structural design sensitivity analysis for path dependent problems. II. Analytical examples," Computer Methods in Applied Mechanics and Engineering, vol. 81, no. 2, pp. 209-228, 1990.

[13] J. L. Chenot, E. Massoni, and L. Fourment, "Inverse problems in finite element simulation of metal forming processes," Engineering Computations, vol. 13, no. 2-4, pp. 190-225, 1996.

[14] S. Badrinarayanan and N. Zabaras, "A sensitivity analysis for the optimal design of metal-forming processes," Computer Methods in Applied Mechanics and Engineering, vol. 129, no. 4, pp. 319-348, 1996.

[15] N. H. Kim, K. K. Choi, and J. S. Chen, "Die shape design optimization of sheet metal stamping process using meshfree method," International Journal for Numerical Methods in Engineering, vol. 51, no. 12, pp. 1385-1405, 2001.

[16] R. Mahnken and E. Stein, "A unified approach for parameter identification of inelastic material models in the frame of the finite element method," Computer Methods in Applied Mechanics and Engineering, vol. 136, no. 3-4, pp. 225-258, 1996.

[17] A. Constantinescu and N. Tardieu, "On the identification of elastoviscoplastic constitutive laws from indentation tests," Inverse Problems in Engineering, vol. 9, no. 1, pp. 19-44, 2001.

[18] G. Bolzon, G. Maier, and M. Panico, "Material model calibration by indentation, imprint mapping and inverse analysis," International Journal of Solids and Structures, vol. 41, no. 11-12, pp. 2957-2975, 2004.

[19] G. Rauchs, "Optimization-based material parameter identification in indentation testing for finite strain elasto-plasticity," Zeitschrift für Angewandte Mathematik und Mechanik, vol. 86, no. 7, pp. 539562, 2006.

[20] S. H. Chung, L. Fourment, J. L. Chenot, and S. M. Hwang, "Adjoint state method for shape sensitivity analysis in non-steady forming applications," International Journal for Numerical Methods in Engineering, vol. 57, no. 10, pp. 1431-1444, 2003.

[21] Q. Zhang and Y. W. Leung, "An orthogonal genetic algorithm for multimedia multicast routing," IEEE Transactions on Evolutionary Computation, vol. 3, no. 1, pp. 53-62, 1999.

[22] Y. W. Leung and Y. Wang, "An orthogonal genetic algorithm with quantization for global numerical optimization," IEEE Transactions on Evolutionary Computation, vol. 5, no. 1, pp. 41-53, 2001.

[23] Z. Hui and T. Guobao, "Structural analysis of modular press machine based on quasi-static approach," Machine Tool E Hydraulics, vol. 11, pp. 100-102, 2005.

[24] Z. Shengdun, W. Jun, and B. Zhenyue, "Optimum design of the structure of flange supported hydraulic cylinder by genetic algorithms," Forging E Stamping Technology, vol. 33, pp. 95-98, 2008. 
[25] P. F. Dubois, "Python: batteries included," Computing in Science and Engineering, vol. 9, no. 3, Article ID 4160249, pp. 7-9, 2007.

[26] S. S. Adams, N. Karst, and J. Pollack, "The minimum decoding delay of maximum rate complex orthogonal space-time block codes," IEEE Transactions on Information Theory, vol. 53, no. 8, pp. 26772684, 2007.

[27] X.-B. Liang, "Orthogonal designs with maximal rates," IEEE Transactions on Information Theory, vol. 49, no. 10, pp. 2468-2503, 2003.

[28] V. Tarokh, H. Jafarkhani, and A. R. Calderbank, "Space-time block codes from orthogonal designs," IEEE Transactions on Information Theory, vol. 45, no. 5, pp. 1456-1467, 1999.

[29] J. D. Kim and E. S. Lee, "A study of ultrasonic vibration cutting of carbon fibre reinforced plastics," International Journal of Advanced Manufacturing Technology, vol. 12, no. 2, pp. 78-86, 1996.

[30] J. S. Dhupia, B. Powalka, A. Galip Ulsoy, and R. Katz, "Effect of a nonlinear joint on the dynamic performance of a machine tool," Journal of Manufacturing Science and Engineering, Transactions of the ASME, vol. 129, no. 5, pp. 943-950, 2007.

[31] O. Ozsahin, A. Erturk, H. N. Ozguven, and E. Budak, "A closed-form approach for identification of dynamical contact parameters in spindle-holder-tool assemblies," International Journal of Machine Tools and Manufacture, vol. 49, no. 1, pp. 25-35, 2009.

[32] P. Belhumeur, J. Hespanda, and D. Kriegman, "Eigenfaces vs. fisher-faces: recognition using class specific linear projection," IEEE Transactions on Pattern Analysis and Machine Intelligence, vol. 19, pp. 711-720, 1997.

[33] J. Wright, A. Y. Yang, A. Ganesh, S. S. Sastry, and Y. Ma, "Robust face recognition via sparse representation," IEEE Transactions on Pattern Analysis and Machine Intelligence, vol. 31, no. 2, pp. 210-227, 2009.

[34] H. Takenaga, S. Abe, M. Takato, M. Kayama, T. Kitamura, and Y. Okuyama, "Input layer optimization of neural networks by sensitivity analysis and its application to recognition of numerals," Electrical Engineering in Japan, vol. 111, no. 4, pp. 130-138, 1991. 


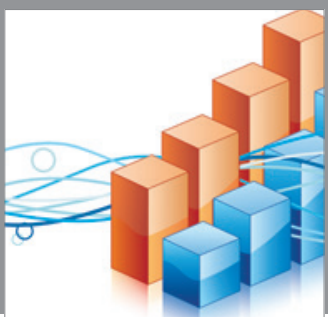

Advances in

Operations Research

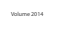

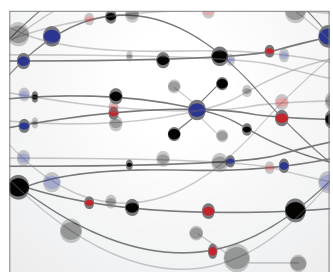

\section{The Scientific} World Journal
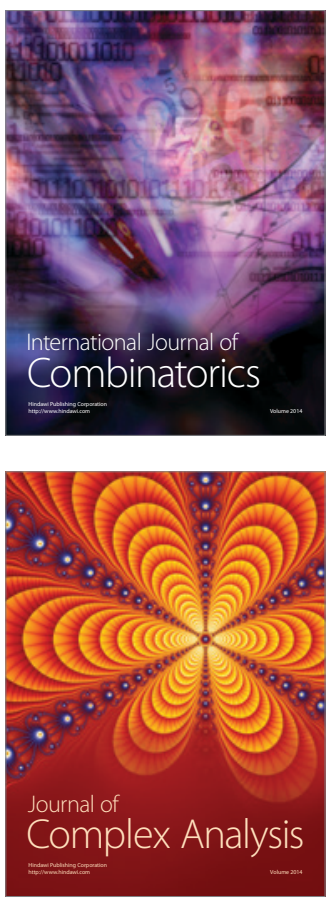

International Journal of

Mathematics and

Mathematical

Sciences
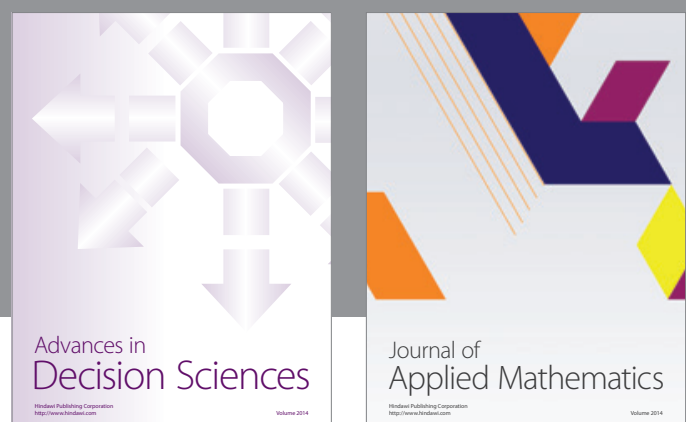

Journal of

Applied Mathematics
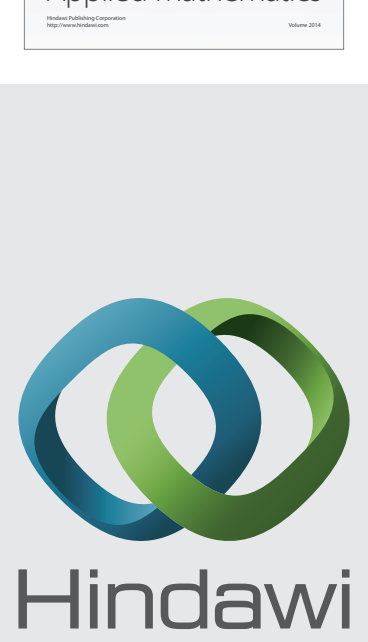

Submit your manuscripts at http://www.hindawi.com
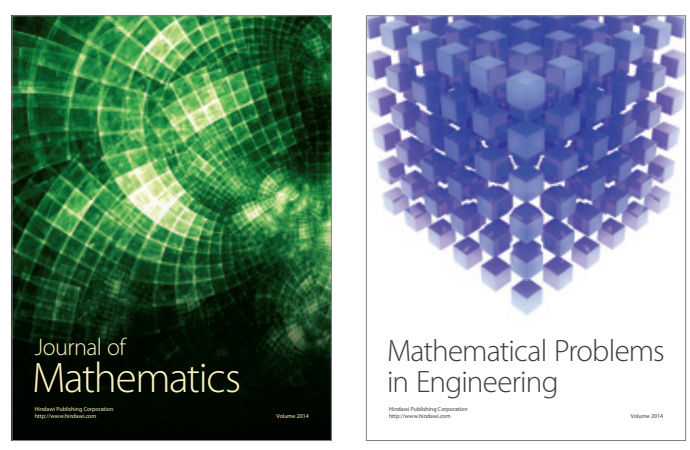

Mathematical Problems in Engineering
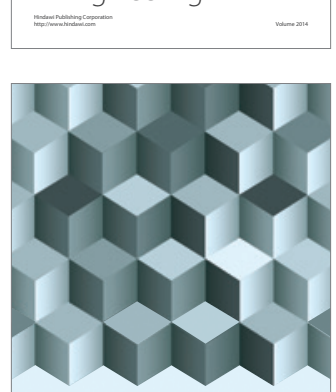

Journal of

Function Spaces
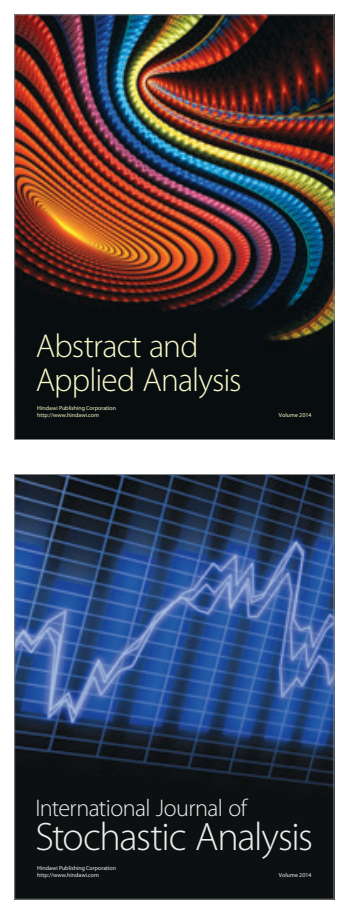

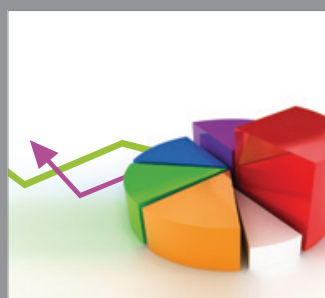

ournal of

Probability and Statistics

Promensencen
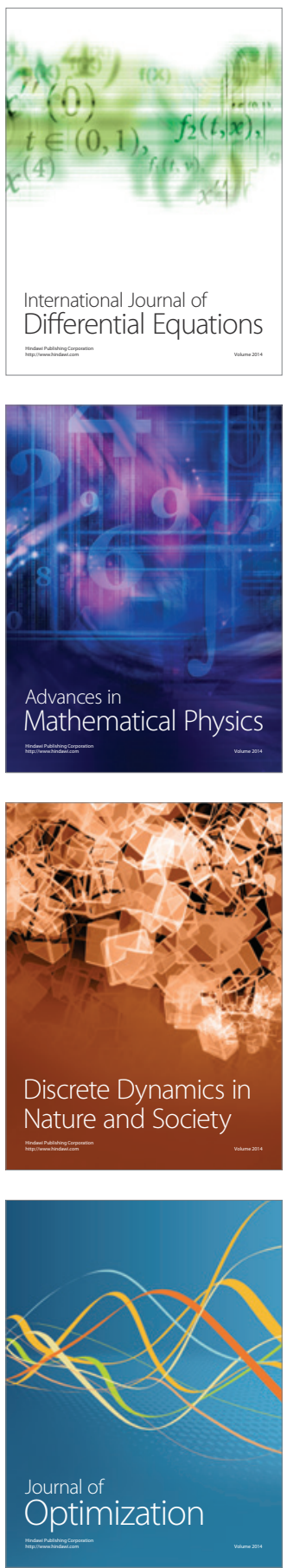